\title{
El acceso a la justicia
}

y la tutela judicial

efectiva en relación

con la seguridad

ciudadana

en Ecuador* / Access

to Justice and to

Effective Judicial

Protection with Respect

to Citizen Security

in Ecuador

* Recibido: 22 de enero de 2015. Aceptado: 27 de febrero de 2015.

Tla-Melaua, revista de Ciencias Sociales. Facultad de Derecho y Ciencias Sociales. Benemérita Universidad Autónoma de Puebla, México / IssN: 1870-6916 / Nueva Época,

Año 9, No 39, octubre 2015/marzo 2016, pp. 58-78. 
La Constitución de la República en su artículo 393 establece: "El Estado garantizará la seguridad humana a través de políticas y acciones integradas, para asegurar la convivencia pacífica de las personas, promover una cultura de paz y prevenir las formas de violencia y discriminación, y la comisión de infracciones y delitos. La planificación y aplicación de estas políticas se encargará a los órganos especializados en los diferentes niveles de gobierno". Entendiendo que la seguridad ciudadana está en construcción, el presente artículo refleja el resultado de investigaciones que se realizan en la carrera de Derecho de la Universidad Metropolitana del Ecuador con la finalidad de contribuir a la concientización no sólo de los derechos y garantías constitucionales, sino de las obligaciones, fundamentalmente aquellas que promuevan el buen vivir con los demás. En ese sentido, se realiza un análisis de la contribución de las transformaciones de la justicia en Ecuador a la seguridad ciudadana relacionadas con las garantías de acceso a la justicia y tutela judicial efectiva.

\section{PALABRAS CLAVE}

Derechos, deberes, seguridad ciudadana, acceso a la justicia, tutela judicial efectiva.
The article 393 of the Republic's Constitution establishes: "The State shall guarantee human security through policies and integrated actions to ensure the peaceful coexistence of the people, to promote a culture of peace and to prevent the forms of violence and discrimination, and the commission of offenses and crimes. The planning and implementation of these policies will be in charge of the specialized bodies in the different levels of government".

Considering that the citizen security is in construction, this paper reflects the outcome of investigations that are carried out in the Faculty of Law in the Universidad Metropolitana del Ecuador (Metropolitan University of Ecuador) with the aim to contribute to the awareness, not only of constitutional rights and guarantees, but obligations, mainly those that promote a good life with others.

Thus, an analysis is made of the contribution of justice's transformations in Ecuador to citizen security related to guarantees of access to justice and effective judicial protection.

KEYWORDS

Rights, Duties, Public Safety, Access to Justice, Effective Judicial Protection.

\footnotetext{
* Docente titular en la Universidad Metropolitana del Ecuador, sede Machala. (silzam_79@hotmail.com)
} 
1. Introducción / 2. Visión actual de la seguridad ciudadana / 3. Estructura constitucional de la seguridad ciudadana / 4. El acceso a la justicia y derecho a la tutela judicial efectiva como garantía de la seguridad ciudadana / 5. Conclusiones

\section{INTRODUCCIÓN}

La Constitución de la República constituye la garantía máxima de cumplimiento de los derechos aplicables de forma inmediata y directa a todos los habitantes en el Ecuador como Estado constitucional de derechos y justicia. Garantizan a la sociedad, a través de políticas y acciones, una convivencia pacífica de las personas y el disfrute del buen vivir. En ese orden, actualmente se instituye la seguridad integral como un cúmulo de acciones encaminadas al cumplimiento del objetivo: garantizar la paz.

$\mathrm{Al}$ respecto, el presidente constitucional de la República, Rafael Correa Delgado, en la presentación de la Agenda Nacional de Seguridad Ciudadana y Gobernabilidad expresó:

La seguridad integral no se alcanza con esfuerzos aislados, por el contrario, exige el auténtico compromiso de todos y todas, desde los más diversos ámbitos. De la misma manera, es indispensable orientar una inmediata transformación cultural, tendiente a ratificar la convicción de que somos un país de paz y que queremos vivir sin violencia, para precautelar nuestra sana convivencia. ${ }^{1}$

De lo anterior se colige que la seguridad ciudadana tiene el significado de prevención contra todo riesgo que tuvieren los derechos fundamentales de las personas, familias y comunidades, fundamentadas en la naturaleza, confianza en el orden jurídico, y en pautas razonables de previsibilidad, que es presupuesto y función de los Estados de derecho. En tal sentido, la misma se constituye en favor de los ciudadanos en un derecho y una garantía que el Estado debe proporcionar mediante diversas políticas públicas.

${ }^{1}$ Correa Delgado, Rafael, Agenda Nacional de Seguridad Ciudadana y Gobernabilidad, Quito, Manthra editores, 2011 , p. 8. 
La sociedad está en un constante proceso de cambio en función del bienestar de sus integrantes, del progreso social, económico y tecnológico. Por tanto, debemos partir de la premisa de que la seguridad es un concepto en construcción. Se considera necesario investigar qué implica la seguridad ciudadana, cuáles son los deberes y derechos que como ciudadanos tenemos, al amparo de la Constitución de la República del Ecuador, y cómo se garantiza dicha seguridad.

Una de las particularidades de la Constitución ecuatoriana de 2008 es la gama de derechos y garantías basados en el reconocimiento de la dignidad individual, colectiva y el Sumak Kawsay o "buen vivir". Sin embargo, sobre esta temática el presidente ecuatoriano ha señalado: "En respuesta a la voluntad del pueblo ecuatoriano, expresada en las urnas, el 7 de mayo de 2010, al aprobar la consulta popular, hoy está en marcha la transformación total de la justicia, paso gigantesco de lucha contra la impunidad, atrapada en la incapacidad y la corrupción, pues no habrá seguridad mientras no acabemos con la impunidad, que es sinónimo de injusticia". ${ }^{2}$

En el Plan Nacional para el Buen Vivir, el tema de la seguridad integral, en lugar de presentarse en forma dispersa en varios objetivos, está articulado hacia la transformación del sistema de justicia. Forma parte sustantiva del objetivo 6: "Consolidar la transformación de la justicia y fortalecer la seguridad integral, en estricto respeto a los derechos humanos". ${ }^{3}$

Tomando en cuenta esas importantes transformaciones que se han realizado en los últimos años en el ámbito de la justicia, resulta pertinente delimitar el presente estudio, con el objetivo de analizar cómo contribuye la garantía de acceso a la justicia y tutela judicial efectiva a la seguridad ciudadana en Ecuador.

\section{VISIÓN ACTUAL DE LA SEGURIDAD CIUDADANA}

A todas luces, la seguridad es una construcción permanente de la vida cotidiana. El término ha generado mucha polémica debido a los múltiples conceptos prevalecientes e interrelacionados (seguridad nacional, pública, integral, humana, ciudadana y jurídica).

Previo al uso del concepto de seguridad ciudadana se utilizaba el de orden público, cuyas técnicas de intervención en la esfera de la libertad de los particulares se efectuaban para tutelar una seguridad concebida en un sentido muy amplio y vinculada con la seguridad del Estado. En los contextos de derechos y libertades, que constituyen la propia esencia del Estado social y

\footnotetext{
${ }^{2}$ Ibid., pp. 7-8.

${ }^{3}$ Secretaría Nacional de Planificación y Desarrollo, Senplades, Plan Nacional para el Buen Vivir 2013-2017, Quito, 2013, p. 83.
} 
democrático de derecho, el concepto de orden público se ha ido desechando por su connotación policial. Las tareas de mantenimiento del orden quedan siempre a cargo de los cuerpos policiales, cuya actuación responde tradicionalmente a la mera constatación de la adecuación de conductas a normas.

Dicho concepto está superado por el de seguridad ciudadana o seguridad pública, según se trate. Las sociedades de corte democrático no pueden partir de una idea de orden como producto o expresión de una voluntad colectiva, clara y precisa interpretada por las normas. Sólo las dictaduras o los Estados de corte represivo pueden seguir manteniendo la ficción de un solo y exclusivo orden social.

En un Estado democrático y progresista, la seguridad es un factor coadyuvante del bienestar social y de la calidad de vida. El desenvolvimiento de una nueva cultura y la concepción de la seguridad no deben estar circunscritos únicamente a la prevención o persecución del delito; deben estar orientados a promover las salvaguardas y la garantía de todos los derechos humanos.

La seguridad aparece como una noción difusa y de límites indefinidos, por lo que actualmente experimenta un nuevo desarrollo. En opinión de Carrión, ${ }^{4}$ la seguridad ciudadana se diferencia de la seguridad nacional o pública, en tanto estas últimas se constituyen desde una concepción Estadocéntrica; la primera, desde la ciudadanía. "Por eso, la seguridad ciudadana se obtiene en un Estado social de derecho donde la libertad del 'respeto al derecho ajeno' es legal, legítima y democrática (igualdad y diversidad). En suma, es la función socializadora que provee la sociedad y sus instituciones: la confianza." ${ }^{5}$

El enfoque integral hace referencia al sentido de un sistema integrado de seguridad, que abarca todos los ámbitos del ser humano y del Estado, sin dejar nada al azar. Tiene que ver con la integración de todas las esferas de la seguridad, las cuales se complementan y se integran en un solo sistema: el sistema de seguridad pública y del Estado. Ahí encontramos la seguridad internacional, la seguridad interna, la defensa nacional, la seguridad económica, la soberanía alimentaria y la seguridad ambiental, entre otras.

La seguridad con enfoque integral es la condición que tiene por finalidad garantizar y proteger los derechos humanos y las libertades, la gobernabilidad, la aplicación de la justicia, el ejercicio de la democracia, la solidaridad, la reducción de vulnerabilidades, la prevención, protección, respuesta y remediación ante riesgos y amenazas.

Como señala Espejel Espinoza: "Una estrategia integral, sin duda, abarcaría los aspectos políticos, sociales, económicos y culturales del problema de

\footnotetext{
${ }^{4}$ Carrión, Fernando, "La inseguridad ciudadana en América Latina", Quórum Revista Iberoamericana-Universidad de Alcalá, otoño 2005, p. 32.

${ }^{5}$ Ibid., pp. 32-33.
} 
la seguridad. Aunado a esto, su construcción, implementación y vigilancia estarían acorde con los principios democráticos que el Estado asume" .

A diferencia de los conceptos tradicionales de seguridad, cuya razón de ser era el Estado, este nuevo enfoque sitúa al ser humano como eje principal y transversal, incorporando a la ciudadanía como actor protagónico de los procesos de seguridad individual y colectiva. Este alcance integral recoge la visión multidimensional de la seguridad, la cual incluye las amenazas tradicionales y las nuevas, preocupaciones y otros desafíos de la seguridad; además, incorpora las prioridades de cada Estado, contribuye a la consolidación de la paz, al desarrollo integral y a la justicia social. Por último, se basa en valores democráticos de respeto, la promoción y defensa de los derechos humanos, la solidaridad, la cooperación y la soberanía nacional.

El concepto de seguridad del Estado de derecho se preocupaba únicamente por garantizar el orden como una expresión de la fuerza y supremacía del poder del Estado. Los Estados democráticos de derecho promueven modelos policiales acordes con la participación de los habitantes, bajo el entendimiento de que la protección de los ciudadanos por parte de los agentes del orden debe darse en un marco de respeto de la institución, las leyes, pero siempre pensados desde la represión y la contención.

Por el contrario, desde la perspectiva de los derechos humanos y el Estado constitucional de derechos y justicia, la seguridad no se limita a la lucha contra la delincuencia; también se dirige a crear un ambiente propicio para la convivencia pacífica de las personas en contextos de igualdad y justicia social.

Por ello, el concepto de seguridad debe poner mayor énfasis en el desarrollo de políticas públicas de prevención y control de los factores que generan violencia e inseguridad, que en tareas meramente represivas o reactivas ante hechos consumados. En razón al enfoque expuesto, el concepto de seguridad ciudadana es el más adecuado para el abordaje de los problemas de criminalidad y violencia desde una perspectiva de derechos humanos, en lugar de los conceptos de seguridad pública, seguridad humana, seguridad interior $\mathrm{u}$ orden público.

Este deriva pacíficamente hacia un enfoque centrado en la construcción de mayores niveles de ciudadanía democrática, con el ciudadano o ciudadana, el pueblo o la nacionalidad indígena como objetivo central de las políticas, a diferencia de la seguridad del Estado o el de determinado orden político. La seguridad ciudadana se logra con la participación de todos y todas. La democracia se consolida porque la ciudadanía participa permanentemente con el Estado. Su concepto no puede alejarse del de solidaridad ciudadana.

\footnotetext{
${ }^{6}$ Espejel Espinoza, Alberto, "Seguridad y democracia: hacia un enfoque integral", Diálogos Multidisciplinarios, México, núm. 2, 2012, pp. 39-49.
} 
En este orden de ideas, se debe entender la seguridad como la condición que permite ampliar las opciones de los individuos, que van desde el disfrute de una vida prolongada y saludable, el acceso al conocimiento y a los recursos necesarios para lograr un nivel de vida digna, hasta el goce de las libertades y los derechos económicos sociales y culturales (derechos del buen vivir).

En lo referido a esta temática, el debate nacional en Ecuador ha estado centrado en dos aspectos. El primero se refiere a la atención de la violencia desde la perspectiva de un Estado fuerte. Ejemplo de ello es lo que establece la Ley de Seguridad Pública y del Estado en el artículo 23:

La seguridad ciudadana es una política de Estado, destinada a fortalecer y modernizar los mecanismos necesarios para garantizar los derechos humanos, en especial el derecho a una vida libre de violencia y criminalidad, la disminución de los niveles de delincuencia, la protección de víctimas y el mejoramiento de la calidad de vida de todos los habitantes del Ecuador. Con el fin de lograr la solidaridad y la reconstitución del tejido social, se orientará a la creación de adecuadas condiciones de prevención y control de la delincuencia y se privilegiarán medidas preventivas y de servicio a la ciudadanía como la ejecución de programas ciudadanos.

El segundo aspecto se refiere a la relación entre seguridad ciudadana y derechos humanos, consagrada en el texto constitucional de 2008. El Ecuador está en concordancia con los conceptos de seguridad humana, los cuales desde hace más de una década han venido debatiéndose y desarrollándose en el nuevo paradigma de la seguridad centrada en el ser humano. La seguridad humana es la condición necesaria para la subsistencia y calidad de vida de las personas y sociedades. Sus componentes abarcan la seguridad económica, alimentaria, sanitaria, ambiental, política, comunitaria y personal. Atiende, justamente, todas las necesidades para el bienestar del ser humano.

$\mathrm{Al}$ respecto, el Plan Nacional para el Buen Vivir reconoce:

En el plano de la seguridad, es importante destacar que una sociedad libre de violencia y temor es del todo deseable, pero improbable en la práctica. Por ello, el desafío de la política pública es generar esfuerzos de gestión, sinergias institucionales y articulaciones entre Estado y sociedad para reducir progresivamente estos problemas en el territorio, desde una perspectiva de derechos humanos y democracia. ${ }^{7}$

\footnotetext{
${ }^{7}$ Secretaría Nacional de Planificación y Desarrollo, Senplades, op. cit., p. 201.
} 
La Constitución de 2008 reconoce que la seguridad es un derecho fundamental de los ecuatorianos y el Estado es el responsable de su pleno ejercicio. La seguridad no es un fin en sí mismo, sino un medio para conseguir el Sumak karesay.

La Constitución de la República se refiere a la seguridad ciudadana como una garantía en sus artículos 3, 83, 158, 163, 341, y 393, sin que sean los únicos. Algunos de ellos abordan la cuestión desde la perspectiva de los derechos humanos y otros se refieren a la consolidación de un Estado fuerte que garantice la paz y la convivencia social.

En materia de seguridad ciudadana, a partir de la protección de los derechos humanos, la Constitución de la República de Ecuador de 2008, en su artículo 3, establece: "Son deberes primordiales del Estado [...] Garantizar a sus habitantes el derecho a una cultura de paz, a la seguridad integral y a vivir en una sociedad democrática, libre de corrupción". Y en el artículo 341:

El Estado generará las condiciones para la protección integral de sus habitantes, que aseguren los derechos y principios reconocidos en la Constitución, en particular la igualdad en la diversidad y la no discriminación, y priorizará su acción hacia aquellos grupos que requieran consideración especial por la persistencia de desigualdades, exclusión, discriminación o violencia, o en virtud de su condición etaria, de salud o de discapacidad.

Art.- 393 El Estado garantizará la seguridad humana a través de políticas y acciones integradas, para asegurar la convivencia pacífica de las personas, promover una cultura de paz y prevenir las formas de violencia y discriminación y la comisión de infracciones y delitos, y la creación de estas políticas se encargarán los órganos especializados en los diferentes niveles de gobierno.

También se establecen los deberes que tienen los ciudadanos como participantes activos en el logro de la seguridad integral en el artículo 83:

Son deberes y responsabilidades de las ecuatorianas y los ecuatorianos, sin perjuicio de otros previstos en la Constitución y la ley: Numeral 4. Colaborar en el mantenimiento de la paz y de la seguridad. Numeral 5. Respetar los Derechos Humanos y luchar por su cumplimiento. Numeral 7. Promover el bien común y anteponer el interés general al interés particular, conforme al Buen Vivir." 
Esta perspectiva de participación ciudadana está presente en la Ley de Seguridad Pública y del Estado cuando se reconoce la interrelación de un Estado que asume sus responsabilidades y una sociedad activa que coadyuva a estas metas.

En ese mismo sentido, en el Plan Nacional para el Buen Vivir, al referirse a la seguridad ciudadana, se enfatiza:

Es importante reconocer sus múltiples causas de origen, productos de distintos factores o tipos de conflictividad social: patrones culturales, cambios demográficos, desigualdades y discriminaciones estructurales, pérdida de valores, fallas en los procesos de socialización, ineficiencia e indiferencia de las principales instituciones responsables. Para un abordaje integral, se debe también incorporar la participación de otros sectores, como el social, el productivo, los gobiernos locales y la ciudadanía en general, bajo los principios de corresponsabilidad, integralidad y progresividad. ${ }^{8}$

Como expresa Carrión:

Es menester el diseño de estrategias ciudadanas de prevención y control inscritas en visiones de gobierno de la seguridad, que vayan más allá de la policía y del estrecho marco nacional. Es necesario construir una "gobernabilidad de la violencia" que surja de una estrategia que vaya más allá de lo local a lo internacional, pasando por la escala nacional, y que involucre a la sociedad toda. ${ }^{9}$

Por otra parte, para consolidar un Estado fuerte en la lucha contra la violencia y en la preservación del orden público, el texto constitucional establece en el artículo 158:

Las Fuerzas Armadas y Policía Nacional son instituciones de protección de derechos, libertades y garantías de los ciudadanos. La protección interna y el mantenimiento del orden público son funciones privativas del Estado y responsabilidad de la Policía Nacional.

Art.- 163 La Policía Nacional es una institución estatal de carácter civil, cuya misión es atender a la seguridad ciudadana y al orden público, además de proteger el libre ejercicio de los derechos y la seguridad de las personas dentro del territorio nacional. Para el desarrollo de sus

\footnotetext{
${ }^{8}$ Secretaría Nacional de Planificación y Desarrollo, Senplades, op. cit., p. 201.

${ }^{9}$ Carrión, Fernando, "De la violencia urbana a la convivencia ciudadana", en Fernando Carrión (ed.), Seguridad ciudadana ¿espejismo o realidad?, Quito, 2002, p. 55.
} 
tareas la Policía Nacional coordinará sus funciones con los diferentes niveles de gobiernos autónomos descentralizados.

De igual manera, la Ley de Seguridad Pública y del Estado establece en el artículo 3:

Es deber del Estado promover y garantizar la seguridad de todos los habitantes, comunidades, pueblos, nacionalidades y colectivos del Ecuador y de la estructura del Estado, a través del Sistema de Seguridad Pública y del Estado, con el fin de coadyuvar al bienestar colectivo, al desarrollo integral, al ejercicio pleno de los derechos humanos y de los derechos y garantías constitucionales.

Como se expresa en el Plan Nacional para el Buen Vivir:

El concepto de seguridad integral consagrado en la Constitución nos permite una ruptura frente a la tradicional mirada policial y reactiva frente al problema de la inseguridad. Si bien miramos a la Policía, la justicia y la rehabilitación social como pilares fundamentales de la seguridad ciudadana, también reconocemos que sus orígenes son multicausales y las respuestas, multiagenciales. Un abordaje integral de la seguridad ciudadana nos permitirá acometer desde un enfoque preventivo y oportuno el problema de la inseguridad. ${ }^{10}$

Debe destacarse que el Ecuador ha ratificado una gama de tratados internacionales, especialmente en materia de derechos humanos, los cuales han generado tres obligaciones básicas: respeto, garantía y tutela. ${ }^{11}$ De este presupuesto se extrae que el Estado tiene la obligación negativa de respeto: restringir el poder estatal para precautelar los derechos y libertades.

También tiene la obligación positiva de garantía, la cual puede ser cumplida de diferentes maneras, en función del derecho específico que el Estado deba garantizar y de las particulares necesidades de protección de cada uno de los derechos y titulares de los mismos. Esta obligación implica el deber del Estado de organizar todo el aparato gubernamental y, en general, todas las estructuras a través de las cuales se manifiesta el ejercicio del poder público, como la legislación. De tal manera, deben ser capaces de asegurar jurídicamente el libre y pleno ejercicio de los derechos humanos. Como parte de dicha obligación, el Estado debe prevenir las violaciones de los derechos

\footnotetext{
${ }^{10}$ Ibid., p. 200.

${ }^{11}$ García Alarcón, Elizabeth, "Prácticas judiciales, garantías de derechos y carrera judicial", en Santiago Andrade Ubidia y Luis Fernando Ávila Linzán (eds.), La transformación de la fusticia, Quito, Serie Justicia y Derechos Humanos. Neoconstitucionalismo y Sociedad, 2009, p. 224.
} 
humanos, investigar seriamente con los medios a su alcance las que se hayan cometido dentro de su jurisdicción, identificar a los responsables, imponerles las sanciones pertinentes y asegurar a la víctima una adecuada reparación.

El concepto de garantía como control de la actividad total de los poderes del Estado sólo se produce en un Estado social de derecho o, como también se le conoce en la doctrina, en un Estado democrático constitucional. ${ }^{12}$ Los derechos humanos de una persona se efectivizan sólo cuando hay mecanismos sociales suficientes para proteger a esa persona de las amenazas contra el ejercicio de las libertades amparadas por esos derechos.

Como señala Ávila Santamaría: "La Constitución vigente tiene un vínculo directo entre los derechos y la organización del Estado. Este vínculo se evidencia, sobre todo, en las garantías; pero además, todas las instituciones del Estado en el ejercicio de sus facultades han de cumplir los deberes del Estado en el ámbito de su competencia y entre todas han de crear las condiciones para el buen vivir". ${ }^{13}$ En el caso ecuatoriano, la Constitución del 2008 incluye un conjunto amplio de garantías que integran distintos tipos o niveles de tutela jurídica para los derechos. Así, encontramos las garantías normativas, las institucionales, las jurisdiccionales, y una verdadera innovación: las denominadas garantías relativas a las políticas públicas. ${ }^{14}$

Con la vigencia de la Constitución de 2008, el Gobierno ha aplicado y ejecutado políticas sociales, a través de sus diferentes ministerios. Ha creado políticas públicas con base en planes de aplicación efectiva. Es por ello que generó el Plan Nacional de Seguridad Integral, que sustenta su visión y misión en el ser humano, hacia quien se dirigen todos los esfuerzos del Estado para sembrar paz, equidad, seguridad, y cosechar convivencia social o el buen vivir de la ciudadanía. Dicho plan incluye ocho agendas que orientan la gestión de los ministerios y secretarías miembros del sector de seguridad: Agenda Estratégica de Política Exterior; Agenda de Política de Defensa; Agenda de Seguridad Ciudadana y Gobernabilidad; Agenda de Justicia, Derechos Humanos y Cultos; Agenda Política de Gestión de Riesgos; Agenda Nacional de Inteligencia; Agenda de Plan Ecuador y Estrategias de Seguridad Vial. ${ }^{15}$

\footnotetext{
${ }^{12}$ Idem.

${ }^{13}$ Ávila Santamaría, Ramiro, Los derechos y sus garantías..., op. cit., p. 109.

${ }^{14}$ Montaña Pinto, Juan, “Apuntes sobre teoría general de las garantías constitucionales”, en Juan Montaña Pinto, y Angélica Porras Velasco (eds.), Apuntes de Derecho Procesal Constitucional. Tomo 2, Quito, Corte Constitucional del Ecuador para el período de transición, Centro de Estudios y Difusión del Derecho Constitucional, 2012, p. 25.

${ }^{15}$ Ministerio Coordinador de Seguridad, Plan de Seguridad Integral, Quito, Manthra editores, 2011.
} 
4. EL ACCESO A LA JUSTICIA Y DERECHO A

LA TUTELA JUDICIAL EFECTIVA COMO GARANTÍA

DE LA SEGURIDAD CIUDADANA

Siendo la seguridad ciudadana una garantía del Estado ecuatoriano, para que se consolide como un derecho debe cumplirse con la no vulneración de los derechos a la libertad, el respeto a los derechos fundamentales, y el acceso a la justicia. La Constitución de la República establece que todas las personas tienen acceso gratuito a la justicia y a la tutela judicial efectiva, imparcial y expedita de sus derechos e intereses con sujeción a los principios constitucionales. El artículo 76 de la Constitución del Ecuador regula que en todo proceso en el que se determinen derechos y obligaciones de cualquier orden se asegurará el derecho al debido proceso. ${ }^{16}$

El constitucionalismo contemporáneo no se puede comprender sin garantías de los derechos. De hecho, los mecanismos normativos, procesales y sociales que aseguran el cumplimiento de ellos son el rasgo más distintivo del Estado constitucional. Indican el claro avance que ha supuesto este modelo de Estado respecto al Estado legal, con su exacerbada preocupación por la ley incluso por sobre la justicia, y del Estado social, que a pesar de tener un amplio catálogo de derechos, incluidos los sociales, carecería de instrumentos que hagan posible su cumplimiento. ${ }^{17}$

En este punto, es necesario recordar que la obligación de tutela de los derechos fundamentales se encuentra contenida en la Convención Americana sobre los Derechos Humanos, en los artículos 25, 8, Números 1 y 2, literal h. Conforme a ellos, el Estado deberá no sólo garantizar el cumplimiento de todas las garantías del debido proceso, entre ellas la de recurrir de un fallo de primera instancia, sino además generar recursos adecuados e idóneos para precautelar la situación jurídica infringida, y lograr la verdadera consecución de la justicia.

La ejecución de las penas, así como de las medidas cautelares personales, debe ser controlada de forma constante en sede judicial. Los derechos de las personas privadas de la libertad deben ser susceptibles de garantía por vía judicial, mediante recursos adecuados, defensa gratuita, exoneración de tasas judiciales y cualquier otra medida para garantizar el acceso a la justicia de las personas privadas de su libertad.

En ese sentido, la Constitución de la República del Ecuador, en el artículo 11, dice:

\footnotetext{
${ }^{16}$ El numeral 7 de artículo 76, Constitución de la República del Ecuador, detalla en qué consiste la garantía a la defensa.

${ }^{17}$ Véase en ese sentido, Ávila Santamaría, Ramiro, Los derechos y sus garantías, ensayos críticos, Quito, Corte Constitucional para el período de transición, 2012, p. 109.
} 
El ejercicio de los derechos se regirá por los siguientes principios: [...] Los derechos y garantías establecidos en la Constitución y en los instrumentos internacionales de derechos humanos serán de directa e inmediata aplicación por y ante cualquier servidora o servidor público, administrativo o judicial, de oficio o a petición de parte. De conformidad a la norma citada, no hay prerrequisitos para ejercer los derechos y las garantías constitucionales, no se exigirán condiciones o requisitos que no estén establecidos en la Constitución o la ley.

La tutela judicial efectiva es uno de los derechos reconocidos con el rango de fundamental por el artículo 75 de la Constitución de la República del Ecuador. ${ }^{18}$ Sistemáticamente, dicho artículo concuerda con las disposiciones del Código Orgánico de la Función Judicial. ${ }^{19}$ La tutela judicial de los derechos se considera como un principio para la administración de justicia que deben observar jueces y juezas al momento de avocar conocimiento de una causa y resolver.

Este principio es de vital trascendencia en la administración de justicia (operadores de justicia). Algunos jurisconsultos españoles discuten si la tutela judicial efectiva es un auténtico derecho de carácter subjetivo, o si por el contrario ha de ser considerada como un mecanismo de aplicación y defensa de otros derechos fundamentales. Un sector doctrinal, encabezado por DíezPicazo Giménez, ${ }^{20}$ afirma que se trata de un auténtico derecho fundamental, que además ha de ser considerado como uno de los más relevantes garantizados por la Constitución.

En la doctrina ecuatoriana, Ávila Santamaría señala que "Los derechos de protección son una herramienta para remover los obstáculos que se presentan cuando los demás derechos son ejercidos. Entre los derechos de protección encontramos el derecho al acceso a la justicia, el derecho a la tutela efectiva". ${ }^{21}$

El criterio para definir lo que debe entenderse por tutela judicial efectiva debería partir entonces por lo más sencillo. Según su significado común, tutela implica alcanzar una respuesta; ciertamente, ello pasa necesariamente por el acceso. Pero no sería correcto concluir a priori que el derecho a la tutela judicial efectiva queda satisfecho con el mero acceso a la jurisdicción. Es preciso entonces que tal apertura sea correspondida con una decisión sobre el fondo del asunto, que reúna los requisitos constitucionales y legales del caso, y la garantía para los justiciables de que sus pretensiones serán resueltas con criterios jurídicos razonables.

\footnotetext{
${ }^{18}$ Constitución de la República del Ecuador. Capítulo octavo "Derechos de Protección", artículo 75.

${ }^{19}$ Código Orgánico de la Función Judicial. Capítulo II. "Principios rectores y Disposiciones Fundamentales", artículo 23. Principios de Tutela Judicial Efectiva de los Derechos.

${ }^{20}$ Díez-Picazo Giménez, Luis María, Sistema de derechos fundamentales, Valencia, Tirant lo Blanch, 2008, p. 95.

${ }^{21}$ Ávila Santamaría, Ramiro, Los derechos y sus garantías..., op. cit., p. 108.
} 


\subsection{La transformación de la administración de justicia en Ecuador como presupuesto fundamental de la seguridad ciudadana}

En opinión de Carrión:

Como la violencia recrudece cuando la sociedad no logra institucionalizar mecanismos no violentos de resolución de conflictos, es hora de modernizar y descentralizar el sistema judicial en su conjunto, para hacerlo menos politizado y más eficiente. Por otro lado, hay que reducir la conflictividad judicial, por ejemplo, con la introducción de la justicia comunitaria, la conciliación y el arbitraje para descongestionar el sistema judicial, y con la puesta en práctica de agencias comunitarias, comisarías de familia o de género. En otras palabras, es el momento para introducir mecanismos alternativos de solución de conflictos que respeten la diversidad y de que se pongan a prueba aspectos de la justicia consuetudinaria. ${ }^{22}$

La constante transformación y mejoramiento de la administración de justicia es un presupuesto insoslayable para la garantía de la seguridad ciudadana. Como señala Ávila Linzán: "En el caso ecuatoriano, esta opción está inspirada en la Constitución del 2008, según la cual la reforma debe ir hacia la máxima garantía del acceso sustancial a la justicia con el fin de transformarla para realizar el 'Estado constitucional de derechos y justicia'". ${ }^{23}$

Como se señala en el Plan Nacional para el Buen Vivir:

El acceso a una justicia imparcial e independiente y la vida en un entorno libre de amenazas, violencia y temor son bienes públicos fundamentales para alcanzar el desarrollo integral de las personas, mejorar su calidad de vida y lograr el ejercicio pleno de sus derechos y libertades democráticas; todo esto, bajo el estricto apego a los principios nacionales e internacionales en derechos humanos. ${ }^{24}$

La más importante transformación a la que debe hacerse referencia es a la constitucionalización del sistema de administración de justicia. ${ }^{25}$ En opinión de Aguirre Guzmán:

\footnotetext{
${ }^{22}$ Carrión, Fernando, "La inseguridad ciudadana...", op. cit., p. 47.

${ }^{23}$ Ávila Linzán, Luis Fernando, "Introducción”, en Santiago Andrade Ubidia y Luis Fernando Ávila Linzán (ed.), La transformación de la fusticia, Quito, Neoconstitucionalismo y Sociedad, 2009, p. Xxv.

${ }^{24}$ Secretaría Nacional de Planificación y Desarrollo, Senplades: ob. cit., p. 200.

${ }_{25}$ Ávila Linzán, Luis Fernando, "Constitucionalización de la administración de Justicia en la Constitución del 2008”, en Ramiro Ávila (ed.), La Constitución de 2008 en el contexto andino: análisis de la doctrina y el derecho comparado, Quito, MJDHC, 2008, pp. 227-283.
} 
Para que la administración de justicia se "constitucionalice", se requiere en esencia, de un poder judicial fuerte, con capacidad de atender las pretensiones legítimas de los ciudadanos, y esto sólo se logra cuando es independiente e imparcial. Se precisa de un número adecuado de juezas y jueces debidamente capacitados, porque de lo contrario, no podrán brindar una tutela adecuada; que cuenten, además, con todos los poderes necesarios para conducir adecuadamente los procesos a su cargo. La transformación de la justicia también demanda contar con herramientas normativas adecuadas, que instrumenten estos anhelos; con edificaciones funcionales, que asimismo sean accesibles a las personas. Es preciso además, una buena coordinación entre todas las instituciones, órganos y personas que conforman el sector justicia y una carrera judicial que garantice que sólo las personas más idóneas, competentes y comprometidas tengan a su cargo la delicada tarea de dirimir conflictos de relevancia jurídica. ${ }^{26}$

Como señala Andrade Ubidia: "Se han producido cambios profundos en los paradigmas; pero, nada se logrará si es que no se toma conciencia de la transformación producida y si no se produce un cambio igualmente radical en los comportamientos de todos los que intervienen en la actividad judicial". ${ }^{27}$

Indudablemente no se puede escribir sobre justicia, aplicación de principios, y de un ordenamiento judicial, sin hacer referencia al rol del juzgador. Éste es pieza fundamental para la efectivización no sólo de los principios constitucionales en orden general, sino en forma específica como garante de la tutela judicial efectiva que a las partes procesales el Estado les ha garantizado, y de la responsabilidad que conllevan sus decisiones. Debe evidenciar con cada una de ellas la existencia de la seguridad jurídica, necesaria como un procedimiento y como un principio que evidencie a los ciudadanos y las ciudadanas credibilidad en la administración de justicia.

La seguridad jurídica involucra desde el perfil mismo del juzgador, forma de haberlo nombrado, hasta la motivación de sus fallos. En consecuencia, los jueces tienen una función específica que nace de la jurisdicción y competencia que les otorga la Constitución de la República y la ley. Por esta razón, son los llamados a resolver los problemas jurídicos puestos en su conocimiento, para lo cual deben otorgar a cada uno de los sujetos procesales lo que le corresponde en derecho.

\footnotetext{
${ }^{26}$ Aguirre Guzmán, Vanesa, "La administración de justicia en Ecuador 2012”, en Gina Benavides Llerena y Gardenia Chávez Núñez (eds.), Horizontes de los derechos humanos Ecuador 2012, Ecuador, Universidad Andina Simón Bolívar, 2012, p. 12.

${ }^{27}$ Andrade Ubidia, Santiago, "Reforma Judicial y Administración de Justicia en el Ecuador de 2008", en Santiago Andrade Ubidia y Luis Fernando Ávila Linzán (eds.), La transformación de la Justicia, Quito, Neoconstitucionalismo y Sociedad, 2009, p. 4.
} 
Para ello, los jueces o magistrados deben tener un conocimiento exacto de las normas jurídicas tanto internas como externas, mismas que deben ser aplicadas en cada caso de sub judice, como parte de la motivación que debe contener cada una de las resoluciones o sentencias, según dispone el artículo 76 numeral 7 literal l) de la Constitución de la República. Para que exista una correcta y completa motivación, es necesario analizar el hecho antijurídico, las pruebas de cargo y de descargo aportadas por los sujetos procesales, las normas jurídicas aplicables al caso en concreto; de manera especial, se aplicará lo relacionado con las reglas de la sana crítica para valorar cada una de las pruebas que han sido solicitadas, ordenadas, practicadas e incorporadas en la etapa de juicio.

La función del juez o magistrado no debe implicar recomendaciones o sugerencias a ninguno de los litigantes. El juzgador, como parte de la función judicial, asume fundamentalmente el rol de amparar, entre los ciudadanos y el Estado y los particulares, aquellos derechos y garantías consagrados constitucionalmente, aplicando principios de justicia, imparcialidad, igualdad y equidad.

Además, los cambios normativos no pueden ir huérfanos. Debe darse una transformación en el órgano de administración o estamento gubernamental. En esa línea, el aparataje judicial sufrió cambios y transformaciones que involucraron ampliación de competencias y de jurisdicción. De ahí que las comisarías quedaran abolidas para que el espíritu de la ley en su plenitud se ejecute y que sea un judicial el que conozca y resuelva todos los conflictos de orden judicial. Esto conlleva que los juzgados se conviertan en unidades judiciales, que se ejecuten las designaciones y nombramientos de los jueces de paz, y el control de efectividad de los centros de mediación y arbitraje con sujeción a la ley.

Una transformación muy importante en la administración de la justicia estrechamente relacionada con la seguridad ciudadana son las unidades judiciales que atienden los casos de violencia intrafamiliar, fortaleciendo la atención especializada a las víctimas de violencia de género. Al concluir el 2015, existían en Ecuador 340 jueces con competencia para conocer casos de violencia intrafamiliar en 221 cantones del país, junto a fiscales y defensores públicos preparados para afrontar de manera integral este tipo de violencia. Para realizar esta labor, se cuenta con 336 especialistas, entre médicos, psicólogos y trabajadores sociales que brindan atención en las unidades creadas por el Consejo de la Judicatura y se encuentran capacitados para el abordaje integral de la violencia. ${ }^{28}$

\footnotetext{
${ }^{28}$ Informe de Rendición de Cuentas Consejo de la Judicatura, enero 2015-enero 2016. [Consulta: 5 de junio, 2016]. Disponible en: http://www.funcionjudicial.gob.ec/index.php/es/transparencia/transparencia-2016.html
} 
El ordenamiento jurídico constitucional ecuatoriano da vida a la visión humanística y fortalece la intervención directa de agentes promotores de una cultura de paz. Además, fortalece la administración de justicia no sólo con jueces empoderados en derechos humanos, reconocidos ahora como jueces constitucionales, sino también con la incorporación de jueces de paz, que tienen como misión resolver en equidad los conflictos puestos a su conocimiento, que pueden utilizar mecanismos de conciliación. Al finalizar el 2015, se encontraban nombrados 91 jueces de paz, quienes fueron designados por consenso en 70 parroquias en todo el país. ${ }^{29}$

El compromiso de impartir una justicia oportuna eficaz, de calidad y con calidez, se refleja también en el fortalecimiento de otros métodos alternativos de resolución de conflictos, como la mediación. A este procedimiento alternativo se llega directamente a través de los propios centros de mediación del Consejo de la Judicatura, o de otros que se encuentran acreditados. El número de causas con acuerdo ascendió durante el año 2015 a 28 836. Hasta el momento, en Ecuador están acreditados 66 centros de mediación. ${ }^{30}$

Por otra parte, el sistema procesal escrito culmina su ciclo, al ser reemplazado por la oralidad en las materias no penales, con la entrada en vigor, desde el 22 de mayo del 2016, del Código Orgánico General de Procesos (Cogep). Con la entrada en vigencia del Cogep se ha destacado la importancia del sistema adversarial oral. Éste tiene como referencia el sistema oral por audiencias. Es decir, se muta de un sistema inquisitivo, en donde predominaban los escritos, la prueba evacuada en el escritorio, declaraciones de testigos mediante actas, con respuestas cortas y casi siempre sin la presencia del juez; una sentencia con demora y sin motivación.

Ahora, el proceso, en el Cogep, se establece mediante la presentación de la demanda conjuntamente con el anuncio de la prueba que la parte actora posea; luego, en un sistema procesal por audiencias orales, en donde la litigación y casuística procesal se desarrollan con el llamado advesary oral sistems, con cero tolerancia a los incidentes procesales, con una preparación del juez para resolver sobre la marcha situaciones puntuales y con la presentación de recursos procesales de impugnación con diferentes efectos y en el momento apropiado.

\subsection{Acceso a la justicia penal como garantía de la seguridad ciudadana}

El tema de la seguridad ciudadana es amplísimo. Se deben combatir conductas que vulneran derechos. Para ello, debe contarse con una identificación plena de los tipos penales, de las sanciones, competencias y jurisdicciones, para garantizar su cumplimiento. El Estado ecuatoriano, a lo largo de su

\footnotetext{
${ }^{29}$ Idem.

${ }^{30}$ Idem.
} 
vida institucional, ha establecido políticas diversas en torno a garantizar la paz social. Se han tenido como herramientas las normativas penales vigentes en su momento, todas ellas sostenidas en la Constitución de la República.

En el Plan Nacional para el Buen Vivir se establece que: "Existe, además, una correlación estrecha entre el mal funcionamiento de la justicia y los índices de seguridad ciudadana. Una justicia incapaz de sancionar a los reos de manera eficaz es un incentivo a la reiteración del delito". ${ }^{31} \mathrm{El}$ actual ordenamiento jurídico penal, normado por el Código Orgánico Integral Penal (COIP), en sus artículos 2 y 3 , establece que se aplican todos los principios que emanan de la Constitución de la República, de los instrumentos internacionales de derechos humanos y los desarrollados en el (COIP), los cuales contemplan la gratuidad de los servicios y la aplicación de nuevos procesos con base en los principios de celeridad y concentración.

Tanto la normativa penal como la norma constitucional prevén la mínima intervención como principio que legitima la protección de las personas. En ese sentido, constituye una herramienta normativa que tipifica y penaliza las conductas punitivas que causan alarma social o contrarían la paz social y el buen vivir de los ciudadanos, o aquellas que han vulnerado un derecho ajeno.

En el ámbito penal actual, en Ecuador, se pretende que los niveles de delincuencia se reduzcan al mínimo. Mediante políticas de gobierno, se han fortalecido espacios como el de la defensoría pública, los centros de rehabilitación, a través del Ministerio de Justicia, y la misma administración de justicia a través del Consejo de la Judicatura (considerando que una justicia oportuna es una justicia eficaz y de calidad). Las transformaciones en la administración de la justicia son constantes en aplicación a los principios constitucionales. Por ello, incluso el lema del Consejo de la Judicatura en Ecuador es "Hacemos de la justicia una práctica diaria". Indudablemente, sólo con operadores de justicia identificados con el trabajo que deben hacer, tendremos menos presos sin sentencias, y menos causas sin resolver. Obviamente, todo ello aporta a que no exista impunidad.

El derecho adjetivo debe garantizar la existencia de un sistema adversarial con fiscales que promuevan el ejercicio de la acción penal dentro de los principios y fundamentos del sistema acusatorio, con defensores y defensoras públicos que patrocinen técnicamente a las personas acusadas de cometer una infracción y a las personas quienes, por su estado de indefensión o condición económica, social o cultural, no puedan contratar los servicios de defensa legal para la protección de sus derechos; y con juezas y jueces que dirijan el proceso y garanticen los derechos de los participantes procesales.

Todo sistema penal se encuentra en el dilema entre combatir la impunidad y garantizar los derechos de las personas sospechosas de haber cometido

${ }^{31}$ Secretaría Nacional de Planificación y Desarrollo, Senplades, op. cit., p. 201. 
una infracción penal. Si las garantías se extreman, se crearía un sistema que nunca sanciona; si se flexibilizan, se acabaría condenando a la persona inocente. El sistema penal tiene que llegar al término medio para evitar que en la sociedad se toleren injusticias y procurar que exista algo parecido a la paz social en el combate de la delincuencia. Todo ello como balance entre garantía y eficiencia de la justicia penal.

Paralelamente a esto, cabe resaltar que el juez, en el Estado garantista, al dejar de ser boca de la ley, y constituirse en activista, tiene la posibilidad de analizar en cada caso concreto la aplicación o no de las normas jurídicas constitucionales, penales o ambas. Tiene herramientas de interpretación tales como la ponderación, para motivar resoluciones y alcanzar la justicia. ${ }^{32}$

El acceso también se expresa en la creación de una Defensoría Pública que entrega asesoría jurídica gratuita y de calidad a los imputados que carecen de medios para proveerse de una defensa técnica por sí mismos. El Estado aporta el financiamiento de esta defensa. Ha permitido elevar considerablemente los estándares de calidad en la prestación de servicios de asistencia judicial en materia penal, motivando a los abogados a postular a los llamados que la Defensoría periódicamente hará a la comunidad jurídica de concursos públicos. ${ }^{33}$

En la mayoría de los países que han adoptado este sistema de garantismo penal, constituye una garantía constitucional que las partes procesales litiguen en igualdad de armas, con el principio de inocencia del procesado, hasta que no se demuestre lo contrario con una sentencia ejecutoriada en última instancia. El acusado debe contar en todo momento con un defensor. Es obligación del juzgador nombrar un defensor público de no tener un defensor privado. En tal sentido, se han escuchado criterios equivocados respecto a que el Estado protege al acusado-delincuente y desprotege a la sociedad. Es necesario aclarar el tema. Para ello deben valorarse tres perspectivas: una jurídica, una social y otra filosófica. La primera es referente a la práctica efectiva del derecho; las dos siguientes, al fin del derecho en sí mismo.

Para analizar el fenómeno desde la perspectiva jurídica, debe partirse de la idea de que el principio de igualdad ante la ley, categorizado en el derecho internacional de los derechos humanos como norma de ius cogens, es una máxima de aplicación e interpretación de la norma jurídica establecida en el artículo 11 de la Constitución. Dicho principio prescribe:

\footnotetext{
${ }^{32}$ Ejemplo claro de esta posibilidad es el caso de "Los Guardianes del Muro". La Corte Constitucional alemana, ponderando los derechos a la verdad, justicia y reparación de las víctimas directas e indirectas de ejecución extrajudiciales, dejó de aplicar el principio de irretroactividad de la ley y la prescripción de la acción. Así, alcanzó una resolución válida y justa. Schwabe, Jürgen, Furisprudencia del Tribunal Constitucional Federal Alemán, traducción Marcela Anzola Gil y Emilio Maus Ratz, México, 2009, pp. 534-537.

${ }^{33}$ Tavolari Oliveros, Raúl, Prólogo al libro Litigación Estratégica en el Nuevo Proceso Penal Chile, Santiago, Lexis Nexis, 2005, p. 3.
} 
Nadie podrá ser discriminado por razones de etnia, lugar de nacimiento, edad, sexo, identidad de género, identidad cultural, estado civil, idioma, religión, ideología, filiación política, pasado judicial, condición socio-económica, condición migratoria, orientación sexual, estado de salud, portar VIH, discapacidad, diferencia física; ni por cualquier otra distinción, personal o colectiva, temporal o permanente, que tenga por objeto o resultado menoscabar o anular el reconocimiento, goce o ejercicio de los derechos.

Por lo tanto, una primera diferenciación entre ciudadano y delincuente se contrapondría con este principio constitucional. El principio de mínima intervención penal debe asegurar que no se tipifiquen formas de vida, sino actos relevantes que puedan alterar drásticamente la realidad social, sin discriminar a ningún grupo social por sus características o actuaciones.

Dado el periodo de implantación de un nuevo modelo procesal penal y una cultura jurídica marcada por la inexistencia real de una defensoría, en este momento histórico el reto mayor de la defensoría pública consiste en lograr un peso específico dentro del sector justicia y en general de la sociedad ecuatoriana. Con base en esta posición, se debe transitar por un camino de logros estratégicamente planificados. El artículo 439 del Código Orgánico Integral Penal considera a las partes procesales como sujetos procesales. En tal sentido, señala que son: 1) la persona procesada, 2) la víctima, 3) la fiscalía, y 4) la defensa.

La defensa consolida el actuar en los procesos, actuando con una intervención técnica de calidad y calidez, con acceso no sólo para el procesado, sino también para la víctima. El fin de esta visión es detectar prácticas sistemáticas que violenten los derechos fundamentales de los defendidos, e iniciar, con distintas herramientas, la consecución de logros progresivos que tiendan a mejorar la posición de los imputados como un todo. ${ }^{34}$

En opinión de Pazmiño Granizo:

Se ha logrado cubrir alrededor de un 95 por ciento de la demanda de defensa en materia penal, actualmente casi no existe una sola persona privada de la libertad en el Ecuador que no cuente con el patrocinio de un defensor público. El número elevado de casos resueltos ha permitido disminuir sustancialmente el porcentaje de "presos sin sentencia" y se ha contribuido a disminuir la sobrepoblación carcelaria. Más de 15000 personas pobres se han incorporado a los servicios que brinda el Estado cuando sus causas son gestionadas por los diversos motivos. ${ }^{35}$

\footnotetext{
${ }^{34}$ Pazmiño Granizo, Ernesto, "Desafíos y perspectivas para la defensoría pública en el Ecuador", en $\mathrm{La}$ transformación de la Justicia, Quito, Ministerio de Justicia y Derechos Humanos, 2009, p. 322.

${ }^{35}$ Ibid., p. 351. 
Otra contribución importante al acceso gratuito a la justicia es la que realizan los consultorios jurídicos gratuitos. Estos servicios, regulados en el Código Orgánico de la Función Judicial, permiten que otros organismos de la sociedad civil, además de las universidades, ${ }^{36}$ generen servicios de defensa a favor de los sectores más empobrecidos, adicionalmente al servicio público oficial. Para que el servicio sea de calidad y eficiente, se manda que la defensoría pública autorice el funcionamiento de estos consultorios jurídicos gratuitos y establezca estándares de calidad y mecanismos de evaluación para garantizarla. ${ }^{37}$

\section{CONCLUSIONES}

En la concepción actual de la seguridad ciudadana, el acceso a una justicia imparcial e independiente que garantice la tutela judicial efectiva de los derechos y la vida en un entorno libre de amenazas, violencia y temor, es presupuesto indispensable para alcanzar el desarrollo integral de las personas, mejorar su calidad de vida y lograr el ejercicio pleno de sus derechos y libertades democráticas.

La seguridad ciudadana, en Ecuador, es un sistema que reconoce el deber del Estado como garante de la protección integral de sus ciudadanos, a la vez que incorpora la participación de otros sectores, como el social, el productivo, los gobiernos locales y la ciudadanía en general, con el desarrollo de políticas públicas, bajo el estricto apego a los principios nacionales e internacionales en derechos humanos

El acceso a la justicia y el derecho a la tutela judicial efectiva son reconocidos como derechos fundamentales por la Constitución de la República del Ecuador. Pero ponerlos en ejecución son también principios de la administración de justicia que se constituyen en un deber de los juzgadores y contribuyen a la seguridad ciudadana.

En Ecuador, la más importante transformación del sistema de administración de justicia es su constitucionalización. Ha generado cambios sustanciales relacionados con la ampliación de competencias y jurisdicción, las designaciones y nombramientos de los jueces de paz, el control de efectividad de los centros de mediación y arbitraje, la creación de la defensoría pública, la ampliación de los servicios legales gratuitos a través de consultorios jurídicos en las universidades y la implementación de la oralidad en todos los procesos.

\footnotetext{
${ }^{36}$ Para lograr esa finalidad, en la Universidad Metropolitana del Ecuador, sede Machala, se cuenta con un proyecto de vinculación con la sociedad que tiene como objetivo contribuir al acceso gratuito a la justicia de los sectores con escasos recursos económicos, a través del Consultorio Jurídico gratuito de la umET. Se encuentra acreditado por la Defensoría Pública desde el año 2013. Como actividades del proyecto, se realizan las asesorías y patrocinios a los usuarios que lo requieren y se extienden los servicios de la sede principal a barrios del cantón, esto último en coordinación con el Gobierno Autónomo Descentralizado Municipal de Machala. Además, se desarrollan cursos de capacitación sobre prevención de la violencia de género, con impactos favorables en los asistentes.

${ }^{37}$ Véase, en ese sentido, Pazmiño Granizo, Ernesto, op. cit., pp. 347-349.
} 
